\title{
Designs and estimates for low cost roads in north-east Brazil
}

\author{
W. K. CROSS
}

Dr J. D. G. F. Howe, Senior Lecturer in Highway Engineering for Developing Countries, University of Surrey

How were the expected traffic flows on the tertiary and secondary roads estimated? There appears to be very little hard evidence available on the traffic generating effects of new road constructions in developing countries. Detailed observations of traffic in Kenya have indicated that fiows on feeder roads, even those associated with plantation crops, are usually several orders of magnitude above that required for mere extraction and management. Of far more importance is the social and commercial traffic generated by the inhabitants/work-force.

68. Fig. 7 shows square-cut side drains. Surely these would be very difficult, if not impossible, to maintain by grader, and they would be susceptible to erosion at the top, and scour at the bottom, of their vertical walls?

\section{Mr P. D. Vulliamy, Scott Wilson Kirkpatrick and Partners}

It would be interesting if the Author could provide the engineering characteristics, such as plasticity index, liquid limit, grading and GBR, of the natural materials used for surfacing. In $\S 21$ he mentions that soils of finer grading were mixed with the concretionary gravels. Perhaps he could also give the properties of the mixture.

70. Of particular interest is the traffic for which the roads have been designed. This is given as 300 vehicles/day for a $4.00 \mathrm{~m}$ wide unsurfaced tertiary road and as 4000 vehicles/day for a $6.00 \mathrm{~m}$ wide unsurfaced secondary road, the shoulder widths on both these roads being only $1.00 \mathrm{~m}$. Experience in Africa for unsurfaced roads in areas with an annual rainfall of $2000 \mathrm{~mm}$ show that the secondary roads would be impassable during the wet season, long before these traffic volumes were reached, and even during the dry season would be almost unmotorable. The maintenance described in $\$ \$ 46-60$, i.e. light grading every three months with twice-yearly grading of irregularities and filling in of potholes would be quite inadequate. Even the more lightly trafficked tertiary roads would, in the light of African experience, be quite inadequate as they are only single lane.

71. Could the Author provide any information on how roads in Brazil, surfaced only with naturally occurring materials, perform when subjected to the traffic volumes quoted in the Paper, particularly in the rainfall zone under discussion.

72. As a result of a number of feasibility studies on low cost roads in Africa it has been found that savings in road maintenance costs, vehicle operating costs and time costs normally make it economic to build a road to two-lane standards with a bituminous surfacing when traffic exceeds $200-400$ vehicles/day. The traffic figures quoted in the Paper are so far in excess of these that it would be interesting if the Author could

Paper published: Proc. Insth Civ. Engrs, 1973, 54, Nov., 641-656. 
provide the equivalent construction cost, road maintenance cost and vehicle operating cost figures that would be used in Brazil for an economic analysis.

73. The Paper shows that low cost roads in Brazil are designed to completely different criteria to those used in parts of Africa. The traffic volumes quoted are substantial for this type of road and in Africa roads similar to the Brazilian secondary roads would be constructed to full two-lane standards with a bituminous surfacing. Even the tertiary roads would have a $24 \mathrm{ft}$ wide running surface and could well be bitumenized depending on projected traffic growth.

\section{Mr M. J. A. Dunn, Brian Colquhoun, Hugh O'Donnell and Partners, Zambia}

We have had experience of designing similar standard roads in Zambia, where there are certain climatic and soils similarities. It is noted that where there are not sufficient quantities of laterite for surfacing it is proposed to mix in soils of finer grading. Can the Author comment on the resulting plasticity index of the mixed soil? It is found here that a combination of excess fine material and high plasticity index will lead to a sludge forming on the running surface and subsequent rutting during the rains.

75. The anticipated vehicle capacities seem high for low cost roads, where it is probable that the limiting factor is maintenance cost and not geometry. It would appear that a good case could be made for higher pavement standards for the secondary roads in view of the high proportion of heavy traffic.

76. Were corrugated galvanized metal pipe and multi-plate culverts considered for drainage structures with stone pitched headwalls or bevelled ends? They are cheap to haul and install and would have a longer life than timber. Properly installed they are less susceptible to scour than bank seat abutment short-span bridges. Unless bedrock is close to the surface it is found here that even with slight bed gradients the rapid rise in water level experienced during the rains causes severe scour.

\section{Mr Cross}

In reply to Dr Howe, it was assumed that road traffic would be generated from the following principal sources:

(a) journeys by officials managing the settlement project

(b) marketing of farm produce

(c) timber extraction (secondary roads only)

(d) bus services

(e) miscellaneous traders and traffic generated by reason of the existence of a road system.

Each of these traffic sources, with the exception of the last, is subject to variations controlled by the planned development of the project. It was anticipated that the traffic generated under $(e)$ would be subject to an annual compound growth rate of $4 \frac{1}{2} \%$. This is almost certainly lower than the growth rate which would be assumed for many other situations, but the project was concerned with farming settlements which would be largely self sufficient. Main routes connecting with other towns were intended to by-pass the area.

78. Concerning the side drains it is considered unlikely that they would be maintained by grader although their shallow average depth and the fact that they are square cut should not make this difficult if grader maintenance is required. The vertical walls have been found less susceptible to erosion in these silty soils than inclined walls, the angles of repose of silty soils being either almost vertical or fairly flat. Whether the walls are vertical or inclined should not affect the scour at the bottom of the ditch; the bed gradient probably has more control over this.

79. It is anticipated that in time the side drain walls will collapse in places, particularly when they have not become stabilized by growths of grasses and shrubs and at animal crossing places. It is also likely that the actual drainage course will meander 
over the width of the side drain, but provided it does not erode into the formation berms, this is probably of little consequence. A skilful scraper operator should be able to reduce the likelihood of this by finishing the side drains so as to leave a slight fall across the drain away from the road.

In reply to Mr Vulliamy the engineering characteristics of the natural materials available for surfacing were as given in Table 3 . Samples were taken from surface to a depth of about $0.5 \mathrm{~m}$. No trial mixes of soils were made, but from the results obtained from all the samples it was apparent that little difficulty should be experienenced in producing suitable mixtures.

80. Concerning traffic capacity for the secondary roads, it is regretted that an error in the proof submitted for publication showed 4000 instead of 400 vehicles/day. In the study area, roads of similar construction were seen to cope with these vehicle capacities, sometimes with even less maintenance than that prescribed. In the full feasibility study report it was stated that the designs took into account that all vehicle movement during and shortly following heavy rains would be restricted to the emergency use of light vehicles. This restriction was to be enforced by manned checkbarriers which had been established on roads throughout the settlement area primarily for marketing control. Dust clouds raised by moving vehicles during the dry season in addition to road widths and wet season conditions reduced the vehicle capacity of these roads.

81. Reduced operating and maintenance costs are at least two of the advantages that bituminous surfaced roads built to two-lane standards have over single-lane unsurfaced roads for these vehicle capacities. However in this case there was initially not the money available. One can only hope that as road use increases as the settlement develops and becomes profitable, the authorities will appreciate that the return on investment in road improvement would be worthwhile. The 1970 construction costs were estimated at US $\$ 10000 / \mathrm{km}$, for the tertiary roads, and US $\$ 15000 / \mathrm{km}$ for the secondary roads. Maintenance costs were estimated at US $\$ 400 / \mathrm{km}$ per year and US $\$ 600 / \mathrm{km}$ per year for the tertiary and secondary roads respectively. Present day costs, especially in Brazil, are likely to be several times these quoted. It would be much appreciated if the construction and maintenance costs for similar roads in East Africa could be given and indeed in other countries as well, so that comparisons might be made.

82. It should be mentioned again that the roads described were designed not as 'through routes' but as internal roads to serve an area for developing farm settlements. The roads are not representative of low-cost roads throughout the whole of Brazil. The factors affecting road design vary considerably over such a large country.

Table 3

\begin{tabular}{|c|c|c|c|c|c|c|c|}
\hline \multirow{2}{*}{\multicolumn{2}{|c|}{ Sieve }} & \multicolumn{6}{|c|}{ Pit no. } \\
\hline & & 2 & 3 & 4 & 5 & 8 & 9 \\
\hline $\begin{array}{l}1 \text { in. } \\
\frac{3}{8} \text { in. } \\
\text { No. } 4 \\
\text { No. } 10 \\
\text { No. } 40 \\
\text { No. } 200\end{array}$ & $\begin{array}{l}25.4 \mathrm{~mm} \\
9.5 \mathrm{~mm} \\
4.8 \mathrm{~mm} \\
2.0 \mathrm{~mm} \\
0.42 \mathrm{~mm} \\
0.075 \mathrm{~mm}\end{array}$ & $\begin{array}{r}100 \\
90 \\
71 \\
66 \\
53 \\
20\end{array}$ & $\begin{array}{r}100 \\
85 \\
71 \\
65 \\
63 \\
37\end{array}$ & $\begin{array}{r}100 \\
88 \\
65 \\
45 \\
39 \\
35\end{array}$ & $\begin{array}{r}100 \\
77 \\
49 \\
43 \\
42 \\
14\end{array}$ & $\begin{array}{r}100 \\
86 \\
73 \\
66 \\
64 \\
42\end{array}$ & $\begin{array}{r}100 \\
97 \\
76 \\
65 \\
63 \\
52\end{array}$ \\
\hline \multicolumn{2}{|c|}{$\begin{array}{l}\text { Liquid limit } \\
\text { Plasticity index } \\
\text { CBR }\end{array}$} & $\begin{array}{r}\text { NL } \\
\text { NP } \\
37\end{array}$ & $\begin{array}{r}21 \\
7 \\
34\end{array}$ & $\begin{array}{l}49 \\
37 \\
60\end{array}$ & $\begin{array}{r}\text { NL } \\
\text { NP } \\
42\end{array}$ & $\begin{array}{l}29 \\
12 \\
33\end{array}$ & $\begin{array}{l}41 \\
21 \\
21\end{array}$ \\
\hline
\end{tabular}


83. In reply to Mr Dunn, from the table of test results given, it can be seen that with the exception of samples from pit 4 , the plasticity indices ranged from nil to $21 \%$. A mix might be prepared from these materials to keep the plasticity index within the $6-20 \%$ range recommended for seasonally wet tropical roads. In this particular case the percentages of fine material were high and hence an attempt would be made to keep the plasticity index within the lower part of this range. This would reduce the likelihood of undesirable sludge formation during rains.

84. Corrugated galvanized metal pipe and multi-plate culverts were not used for the following reasons:

(a) the exceptionally long distances over which they would have had to be transported made them considerably more expensive than timber;

(b) no gravels or rock were found in the region and hence suitable headwalls could not have been constructed;

(c) the soils were very acid, and it was considered unlikely that metal structures would have lasted as long as the 15-20 years anticipated for the hardwood construction;

(d) locally available labour was quite skilled in making timber structures, and with timber readily available maintenance was comparatively simple and less likely to be delayed. 